\title{
A imagem da Vera Cruz nos livros
}

Adilson José RuIZ

Universidade Estadual de Campinas/UNICAMP 


\section{Resumo}

Muito se escreveu sobre a Cia. Cinematográfica Vera Cruz nos últimos 50 anos. Neste artigo buscamos fazer uma avaliação dos principais textos e pesquisas produzidos sobre este importante episódio da história do cinema brasileiro. Encontramos nestes textos um claro divisor de águas: o que foi produzido antes da pesquisa de doutoramento da professora Maria Rita Galvão, Companhia cinematográfica Vera Cruz: a fábrica de sonhos, e o que vem sendo realizado depois.

\section{Palavras-chave}

Vera Cruz, cinema brasileiro, Maria Rita Galvão

\section{Abstract}

A lot has been written about Companhia Cinematográfica Vera Cruz in the last 50 years. In this article, we tried to make an evaluation among the greatest texts and researches made about this important episode from Brazilian cinema's history. We've discovered in these texts a happening that shares the history in two ages: what was produced before the doctorate's research from the teacher Maria Rita Galvão called Companhia Cinematográfica Vera Cruz: the dreams' factory, and what has been produced after this.

\section{Key words}

Vera Cruz, brazilian cinema, Maria Rita Galvão 


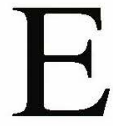

Este artigo é parte da pesquisa, financiada pela Universidade Paulista, que estamos realizando sobre a Companhia Cinematográfica Vera Cruz e que tem entre os seus objetivos a criação de um roteiro ficcional de longa-metragem sobre aquele importante episódio da história do cinema brasileiro.

Em 1954, quando foi lançado o filme dirigido Lima Barreto $O$ cangaceiro, a cidade de São Paulo tinha uma população em torno de 2 milhões de habitantes. Quinhentos mil foi o número de espectadores do filme, cerca de um quarto de sua população. O próximo e último lançamento da Cia. Cinematográfica Vera Cruz, Sinha moça, superou essa marca.

A Vera Cruz, depois de aproximadamente quatro anos de sua fundação, havia finalmente encontrado o reconhecimento do público No entanto, nesse momento a companhia já estava em situação falimentar, e os direitos de distribuição $O$ cangaceiro nas mãos da Columbia. A Cia. já não tinha mais fôlego, e o seu principal empreendedor, o visionário Franco Zampari, já não detinha mais o controle.

Um dos principais motivos do naufrágio do projeto, foi porque os seus idealizadores não souberam avaliar as questões relativas ao mercado consumidor para o filme brasileiro, e bateram de frente com os interesses das grandes corporações americanas que detinham e ainda detêm o controle geopolítico deste mercado, já globalizado desde sua implantação no início do século passado.

Atualmente, momento em que o cinema brasileiro busca novamente lançar pilares de uma tardia indústria cinematográfica, a revisão da história da Vera Cruz pode ser de grande valia para, ao menos, evitar que sejam cometidos os mesmos erros, e que se caia nas mesmas armadilhas. Os problemas conjunturais em que a com- 
panhia se viu enredada, e que acabaram por levá-la à derrota, ainda subsistem. Os fatos e as vicissitudes vividas pelos homens e mulheres que participaram daquele esforço, que por pouco não logrou êxito, são do conhecimento de poucos especialistas, permanecendo desconhecidos da maioria da sociedade brasileira.

Muito se escreveu e disse sobre aquele momento da nossa cinematografia, principalmente sobre os erros que teriam sido cometidos, sempre no sentido de desvalorizar a experiência. Porém, a importância do legado da Vera Cruz para o desenvolvimento posterior da cinematografia brasileira ainda está por ser plenamente demonstrada.

O objetivo principal deste artigo é uma avaliação das principais obras disponíveis sobre a Cia Cinematográfica Vera Cruz. Dos títulos arrolados na bibliografia que ora comentamos podemos identificar dois grupos. Os publicados antes e depois do lançamento do livro de Maria Rita Galvão, Burguesia e cinema: o caso Vera Cruz, em 1981. O texto é o resultado parcial de sua pesquisa de doutorado, que teve a qualidade de, pela primeira vez, coletar dados, documentos, material iconográfico e depoimentos sobre a Companhia Cinematográfica Vera Cruz e a partir deles realizar verticalizações analíticas que redundaram em um conhecimento de fato daquele momento de nossa cinematografia.

\section{Antes}

Até o lançamento do livro, as pesquisas sobre a companhia eram superficiais, em geral refletindo dados imprecisos e, muitos textos, davam curso até mesmo aos boatos e anedotas sobre o relacionamento dos técnicos, artistas e dirigentes que profusamente circulavam no campo do cinema, principalmente em São Paulo e Rio de Janeiro.

Entre os textos publicados antes do livro de Maria Rita, dois se destacam: Introdução ao Cinema Brasileiro de Alex Viany de 1958; e Revisão crítica do cinema brasileiro de Glauber Rocha, publicado em 1963.

Nestes livros os autores enfatizam uma visão negativa da experiência da Vera Cruz, Viany está muito preocupado em demons- 
trar que o projeto Vera Cruz havia nascido para uma morte anunciada e inexorável, enquanto Glauber procura demonstrar que a companhia não passou de um grande equivoco a serviço dos interesses da burguesia internacional.

Logo na primeira página do capítulo dedicado à Vera Cruz, podemos perceber a linha de argumentação de Viany ao destacar a seguinte frase atribuída a Pedro Lima: "Desde o primeiro dia , quando a Vera Cruz ainda não havia iniciado Caiçara (...), prevíramos, e disso fizemos ciente seu diretor, Zampari, o insucesso da companhia, porque, pelos planos que ouvíramos, ela não se firmava em alicerces sólidos". Mais adiante encontramos o seguinte parágrafo: "Disse alguém que, se os inimigos do nosso cinema tivessem planejado um golpe capaz de abalar os alicerces de nossa indústria nascente, não poderiam imaginar um plano tão eficaz como o que foi levado a efeito pela Vera Cruz". Neste trecho podemos perceber a indefinição das fontes e a maledicência que envolveu a Vera Cruz no meio cinematográfico, principalmente no Rio de Janeiro.

Um fato que teve muita responsabilidade por essa animosidade foi um descuido de marketing: a companhia deixou de fazer, sem qualquer aviso, a prometida exibição de sua primeira produção, Caiçara, para a crítica especializada do Rio de Janeiro antes da estréia oficial para a sociedade carioca. Esta gafe nunca foi perdoada pelos críticos do Rio, o que, em parte, explica a constante má vontade da imprensa local para com a companhia.

Constata-se, ainda no texto, a resistência, que surge em diversos críticos da Vera Cruz na época, aos artistas e técnicos estrangeiros convidados a formar o corpo de profissionais, principalmente os italianos que, sem sombra de dúvida, eram em maior número. Viany afirma: "Não é fácil encontrar um bom elemento entre os que Zampari contratou para a companhia antes da chegada de Cavalcanti, ou depois de sua saída. Italianos em sua maioria, eram, nos melhores dos casos, amadores bem intencionados, ou gente de teatro. Nos piores casos, nem é bom falar."

Entre comentários e descrições, nas 13 páginas dedicadas à Vera Cruz, no livro de Viany, a sensação que se tem ao final é que a empresa não passou de um grande equivoco, onde os pontos negati- 
vos superam em muito as eventuais contribuições que ficaram daquela experiência

Glauber, em sua Revisão crítica, não deixa para menos: “A década de cinquienta foi a mais complexa do cinema brasileiro: toda a experiência internacional de Cavalcanti, atuando na própria história do cinema, de nada serviu: a Vera-Cruz continuou para falir em seguida; ruíram Maristela, Multifilmes, Sacra Filmes, Kino Filmes. Uma centena de filmes foram feitos: não sobrou um que prestasse. Claro, nasceu um monstro, O Cangaceiro, que enlouqueceu o pai."

No texto, absolutamente adjetivado, de Glauber Rocha não fica pedra sobre pedra. Segundo sua visão, a experiência industrial tentada pela Vera Cruz e outras companhias que a sucederam foram cultural e mercadologicamente um fracasso. Um modelo que estaria na contramão do cinema mundial. Na sua crítica de terra arrasada, a cada parágrafo uma opinião devastadora: "O que controla uma indústria cinematográfica é planejamento e consciência e perspectivas culturais: na Vera-Cruz havia burrice, auto-suficiência e amadorismo. Era pecado falar em Brasil."

Mais adiante, Glauber, sem informar que quando Cavalcanti integrou a companhia o filme Caiçara já estava decidido, chega a atribuir ao diretor a opção a temas e tratamentos burgueses dados aos filmes: "A experiência da Vera-Cruz, nos anos iniciais de Cavalcanti é denunciadora; Caiçara, dirigida por Adolfo Celli, é um melodrama que envolve personagens burgueses, escondendo a realidade dos habitantes da ilha. A cenografia falsificante se evidencia a cada detalhe, até nas vestes e maquiagem dos atores. Um plano que mostra a chegada de Mário Sérgio na ilha é feito na convenção do cinema americano dos mares do sul."

Para Glauber, no entanto, dentre os males da Companhia, o maior talvez fosse o fato de a direção dos filmes estar entregue aos italianos: "Sim, Cavalcanti não era responsável pelos italianos; mas devia, quando Zampari o convidou, aceitar com a condição de usar somente diretores brasileiros nos estúdios de São Bernardo do Campo(...), com sua experiência, com a técnica dos elementos importados e com o respeito que estes diretores brasileiros devotam a ele, Cavalcanti poderia ter contornado e, com certeza, faria a Vera-Cruz vingar. 
Na conclusão de suas azedas reflexões sobre a Vera Cruz, Glauber Rocha inicia com uma pergunta para que ele mesmo possa responder: "O que ficou da Vera-Cruz? Como mentalidade, a pior que se pudesse desejar para um país pobre como o Brasil. Como técnica, um efeito pernóstico que hoje não interessa aos jovens realizadores que desprezam refletores gigantescos, gruas, máquinas possantes, e preferem a câmera na mão, o gravador portátil, o rebatedor leve, os refletores pequenos, atores sem maquiagem em ambientes naturais. Como produção, um gasto criminoso de dinheiro de filmes que foram espoliados pela Columbia Pictures - quem mais lucrou com a falência, também grande motivo da falência. Como arte, o detestável princípio de imitação, de cópia dos grandes diretores americanos ou de todos aqueles com ligação com o expressionismo(..). Tudo, no final das contas, o que representa de morto antes da segunda guerra - a exceção de nomes como Welles e Bergman."

\section{Depois}

Com relação aos livros e artigos publicados após a pesquisa de Maria Rita Galvão, como os de Antonio Moreno, Hélio Nascimento, e mesmo, a História do cinema Brasileiro, de Fernão Ramos, não aportam nada de novo. Na verdade, todos estes trabalhos estão umbilicalmente ligados ao texto Burquesia e Cinema, a principal fonte de referência, até o presente momento, sobre a Companhia Cinematográfica Vera Cruz. A maioria dos textos acaba referendando aquela obra. É possível até encontrar os mesmos argumentos de Maria Rita para explicar aquela tentativa de criar uma indústria de cinema no Estado de São Paulo, pioneiro no processo de industrialização do país.

Entre estes últimos, destaca-se o texto de Calil, no catálogo do Projeto Memória Vera Cruz. Neste artigo, ele comenta os principais episódios do percurso cinematográfico da companhia, procurando demonstrar que, ao contrário do que se pode concluir pela maior parte das coisas que se falou da Vera Cruz, o projeto não foi um fracasso absoluto e que sua existência teria contribuído para o futuro da cinematografia nacional. 
Calil, na última parte de seu artigo, à semelhança de Glauber, inicia com a mesma pergunta para então responder: "Onde é que se nota hoje a presença da Vera Cruz? No premiado cinema publicitário paulista, praticamente fundado pelos técnicos estrangeiros que repentinamente se viram desempregados com a suspensão das atividades da companhia. Na mentalidade dos profissionais contemporâneos que valorizam o conhecimento e a utilização adequada das tecnologias a seu dispor. Nesse sentido, a Vera Cruz cumpriu plenamente o seu objetivo de formar uma geração de técnicos para o futuro cinema no Brasil."

Nesta conclusão, o articulista ainda enumera vários diretores brasileiros oriundos da Vera Cruz, entre eles Lima Barreto e Galileu Garcia. Lembra ainda que o principal estúdio de som para cinema dos últimos anos, a Álamo, foi fundado por Michael Stoll, inglês que veio com a primeira leva de estrangeiros em 1950. Destaca também, entre outros argumentos, o surgimento do maior fenômeno de bilheteria de todos os tempos no cinema brasileiro, Mazzaropi.

\section{A burguesia e o cinema}

Finalmente, comentaremos a obra de Maria Rita Galvão, o mais profundo e sério trabalho de pesquisa sobre a companhia instalada em 1949 em São Bernardo do Campo, local que veio a se tornar o berço da nascente indústria automobilística que se instalou no país, a partir da década de cinquienta.

$\mathrm{Na}$ nota de abertura do livro Burguesia e cinema: o caso Vera Cruz, ficamos sabendo que o livro é o resultado de uma compilação, proposta e batizada por Jean-Claude Bernardet, de trechos de uma pesquisa maior realizada pela autora Maria Rita Galvão (1975) por ocasião de sua tese de doutorado:

A seleção dos trechos para a primeira publicação foi feita por Jean-Claude, e não obedece exatamente a seqüência em que eles inicialmente se apresentavam.(...) Jean-Claude realizou um corte transversal no trabalho, perseguindo um tema: as relações cinema/burguesia. 
O texto original, bem mais abrangente, era composto de sete partes: a primeira tratava dos antecedentes da Vera Cruz; a segunda, historiava a ascensão e queda da companhia através da transcrição comentada dos jornais da época; na terceira, uma reconstituição da história do ponto de vista das pessoas que participaram da atividade; depois, a derrocada final desde a encampação pelo Banespa até a destruição dos estúdios; a quinta parte era composta de apontamentos sobre os filmes; na sexta, três anexos sobre as companhias Maristela, Multifilmes e Kinofilmes; e na última parte, uma filmografia paulista do período.

No final da nota, uma promessa, até hoje, infelizmente, não cumprida: "As outras partes da pesquisa, reagrupadas em três blocos, serão publicadas separadamente."

Como vimos, o recorte escolhido pelo livro procura demonstrar que o advento da Vera Cruz estava ligado à afirmação da burguesia industrial paulista representada pelos industriais italianos radicados em São Paulo. Segundo Maria Rita, (1975):

A Vera Cruz surge num momento de grande efervescência cultural em São Paulo, um pós-guerra rico de idéias e realizações. Num curto espaço de tempo - cinco, seis anos, talvez - a cidade assiste, um tanto perplexa $e$ orgulhosíssima, ao nascimento de dois museus de arte, à formação de uma companhia teatral de alto nível, à multiplicação de concertos, escolas de arte, conferências, seminários exposições, revistas de divulgação artísticas e cultural, à construção de uma grande moderna casa de espetáculos, à criação de uma filmoteca, à inauguração de uma bienal de artes plásticas a tudo o quanto é sinal de expansão dessa cultura eminentemente urbana e burguesa que distingui a grande cidade da província.

Ainda, segundo a autora, estes fatos não só são financiados por essa burguesia industrial como "claramente se delineia uma postura cultural da burguesia paulista e - pelo menos como hipótese de trabalho - tomamos tais manifestações como infra-estrutura para a ela- 
boração de um sistema de produção cultural que pudesse estenderse para toda a sociedade, veiculando uma determinada visão de mundo. (...) a burguesia não se limita a sustentar artistas que produziriam arte para seu consumo exclusivo, ela cria museus, escolas, teatros todo um equipamento para a difusão da cultura.

Através do quadro de efervescência cultural habilmente montado por Maria Rita, no primeiro capítulo do livro, somos levados a perceber que havia todo um ambiente favorável ao surgimento de mais um grande projeto na área da cultura. Assim, a proposta da criação da Vera Cruz vem coroar este momento de modernização e cosmopolitização da cidade de São Paulo.

Entre estes burgueses amantes das artes havia o bem sucedido engenheiro, diretor da metalúrgica Matarazzo, Franco Zampari, um dos seus principais incentivadores. Nos projetos de Zampari encontrava-se o próprio Cicillo Matarazzo. O Museu de Arte Moderna, a Sociedade de Cultura Artística e o Teatro Brasileiro de Comédia - TBC, são alguns dos projetos financiados por estes capitães da indústria paulista.

Quando os proprietários da Rex Filmes, o principal laboratório de serviços cinematográficos de São Paulo, propõem a Franco Zampari a sociedade na realização de um filme, não imaginavam a proporção que tal proposta ganharia. Assim, em pouco tempo, de um casamento entre TBC e os conhecimentos inicialmente aportados pelos homens da Rex, nasce um ambicioso projeto de uma companhia que deveria finalmente instalar no Brasil uma indústria cinematográfica aos moldes das cinematografias mais desenvolvidas do mundo.

Ainda nesta minuciosa pesquisa, temos a oportunidade de conhecer o teor dos principais documentos relativos à vida da companhia, como, por exemplo, uma reprodução na íntegra dos dois primeiros contratos sociais de instalação da Vera Cruz, com os detalhes de seu capital, de cada uma das cotas e de sua diretoria. Finalmente nos é dado conhecer a opinião e a versão de 17 personalidades ligadas ao projeto, que, em saborosas entrevistas, nos remetem ao dia-adia daqueles incríveis anos em que durou a experiência. 


\section{Bibliografia}

BERNARDET, Jean-Claude. 1977. Brasil em tempo de cinema. Rio de Janeiro: Paz e Terra.

1981. Cinema brasileiro: Propostas para uma história. Rio de Janeiro: Paz e Terra.

; GALVÃO, Maria Rita. 1983. Repercussões em caixa de eco ideológica. AS idéias de 'nacional' e 'popular' no pensamento cinematográfico brasileiro. São Paulo: Brasiliense/ Embrafilme.

CALIL, Carlos Augusto; MACHADO, Maria Teresa (orgs.). 1986. Paulo Emílio - um Intelectual na linha de frente. Rio de Janeiro: Brasiliense/Embrafilme. SCESP.

1987. Projeto memória Vera Cruz. São Paulo: MIS e

GALVÃO, Maria Rita. 1975. Crônica do cinema Paulistano. São Paulo: Ática.

1981. Burguesia e cinema: o caso Vera Cruz. Rio de Janeiro: Civilização Brasileira.

; SOUZA, Carlos Roberto de. 1984. "Cinema Brasileiro: 1030-1964". Histótia Geral da civilização Brasileira, tomo III, O Brasil republicano, $4^{\circ}$ vol., Economia e Cultura, São Paulo: Difel.

GOMES, Paulo Emílio Salles. 1980. Cinema: Trajetória no subdesenvolvimento. Rio de Janeiro: Paz e Terra/Embrafilme.

ORTIZ RAMOS, José Mario. 1983. Cinema, Estado e lutas culturais - anos 50/60/70. Rio de Janeiro: Paz eTerra.

PELLIZZARI, Lorenzo \& VALENTINETTI, Claudio M. 1995. Alberto Cavalcanti: Pontos sobre o Brasil. São Paulo: Instituto Lina Bo e P.M.Bardi.

NASCIMENTO, Hélio. 1981. Cinema brasileiro. Porto Alegre: Mercado Aberto.

MORENO, Antonio. 1994. Cinema brasileiro: hístória e relações com o Estado. Belo, Horizonte: Editora UFMG.

RAMOS, Fernão. 1987. História do cinema brasileiro. São Paulo: Art Editora. 
ROCHA, Glauber. 1965. Revisão crítica do cinema brasileiro. Rio de Janeiro: Civilização Brasileira.

SALLES, Francisco Luis de Almeida. 1988. Cinema e verdade. São Paulo: Companhia das Letras.

SOUZA, Carlos Roberto de.1998. Nossa aventura na tela - A trajetória fascinante do cinema brasileiro da primeira filmagem a "Central do Brasil". São Paulo: Cultura Editores Associados.

VIANY, Alex. 1987. Introdução ao cinema brasileiro. Rio de Janeiro: Alhambra/Embrafilme. 